\title{
Role of Point-of-care Ultrasound Imaging in Neonatal Sepsis
}

\author{
Rema Nagpal ${ }^{1}$, Pradeep Suryawanshi ${ }^{2}$
}

\begin{abstract}
Neonatal sepsis remains a very common cause of morbidity and mortality. Point-of-care ultrasound imaging is a useful tool to determine the site of infection, the progress of sepsis, and prognosis/outcomes of septic neonates. The organ system imaging that is useful includes cardiac ultrasound for delineation of the hemodynamics, cranial imaging for changes in meningitis/ventriculitis, lung ultrasound for early detection of effusions and consolidation, and gut imaging for gut perfusion and viability in necrotizing enterocolitis. We describe the role of ultrasound imaging in the early diagnosis and management of neonatal sepsis.
\end{abstract}

Keywords: Cardiac hemodynamics, Gut ultrasound, Lung ultrasound, Neonates, Point-of-care ultrasound, Sepsis.

Pediatric Infectious Disease (2020): 10.5005/jp-journals-10081-1249

\section{INTRODUCTION}

Sepsis is one of the three most common causes of neonatal deaths globally. ${ }^{1}$ In very low birth weight (VLBW) infants, sepsis has been an important cause of neonatal mortality and morbidity. More than one culture-proven sepsis episodes are seen in $25 \%$ of VLBW infants, and the overall mortality rate is $17 \%$. Infection is the main cause of death in VLBW infants after second week of life which accounts for $40 \%$ of deaths. ${ }^{2}$ Poor neurodevelopmental and growth in early childhood are seen in extremely low birth weight infants with neonatal infections. ${ }^{3}$ Therefore, early recognition and appropriate management is imperative for good outcomes. Point-of-care ultrasound imaging has become a useful tool in the hands of the clinician to determine the site of infection, the progress of sepsis, and prognosis/outcomes of neonates with sepsis.

We aim to describe the role of ultrasound imaging in neonates with signs of sepsis, including the alterations in cardiac hemodynamics and infective pathologies in the lung, gut, and cranial ultrasounds.

\section{Role of Functional Echocardiography in Neonatal Sepsis/Septic Shock}

There are developmental differences in the hemodynamic responses to sepsis in newborns, children, and adults. This has been well articulated by the "American College of Critical Care Medicine Clinical Practice Parameters for Hemodynamic Support of Pediatric and Neonatal Septic Shock" published in $2017^{4}$ and by other authors. ${ }^{5,6}$ Vasomotor paralysis is the predominant cause of mortality in "adult septic shock," leading to low systemic vascular resistance associated with myocardial dysfunction., 4 "Pediatric septic shock" is typically associated with severe hypovolemia, and aggressive volume resuscitation is needed. ${ }^{4}$

At variance from adults and children, neonates are in the process of undergoing a physiologic transition from fetal to neonatal circulation. Initially, the ductus arteriosus can remain open

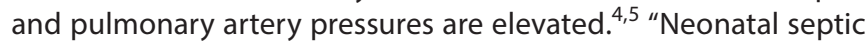
shock" is, therefore, to be viewed alongside these physiological changes. The pulmonary artery pressures increase further due to sepsis-induced acidosis and hypoxia. This results in persistent pulmonary hypertension of the newborn (PPHN). There is increased right ventricular work, manifested as tricuspid regurgitation, right ventricular dysfunction, and hepatomegaly. The delivery of oxygen
${ }^{1}$ BJ Government Medical College and Sassoon General Hospital, Pune, Maharashtra, India

${ }^{2}$ Department of Neonatology, Bharati Vidyapeeth University Medical College, Pune, Maharashtra, India

Corresponding Author: Pradeep Suryawanshi, Department of Neonatology, Bharati Vidyapeeth University Medical College, Pune, Maharashtra, India, Phone: +91 9923540500, e-mail: drpradeepsuryawanshi@gmail.com

How to cite this article: Nagpal R, Suryawanshi P. Role of Point-ofcare Ultrasound Imaging in Neonatal Sepsis. Pediatr Inf Dis 2020;2(3): 89-98.

Source of support: Nil

Conflict of interest: None

and nutrients to tissues is affected by myocardial dysfunction, abnormal peripheral vasoregulation, and hypovolemia. Therapies need to be directed at reversal of right ventricle failure through reduction of pulmonary artery pressures, augmentation of LV contractility, and volume support appropriately. The functional immaturity of the adrenal gland in premature infant results in relative adrenal insufficiency. This could lead to cardiovascular dysfunction. ${ }^{4,7}$

The extra information on hemodynamic state in neonates with sepsis can be obtained by functional echocardiography which is probably the only diagnostic tool. ${ }^{8}$ This aids in choice of inotropic and vasopressor support.

\section{Right Ventricle and Left Ventricle Cardiac Outputs (CO) and} Superior Vena Cava (SVC) Blood Flow Measurements

Measurements of CO and SVC flows need to be done because it could be used to determine the type of inotropic and vasopressor support that may be needed in a clinical situation. ${ }^{9}$ The factors such as preload, contractility, and afterload affects the cardiac output and is a good marker of cardiac dysfunction in preterm infants. Cardiac Output $(\mathrm{CO})=$ Heart Rate $(\mathrm{HR}) \times$ Stroke Volume (SV); therefore, factors affecting SV like sepsis associated endotoxins reduce CO unless there is a compensatory tachycardia. An increase in HR by twofold from 70 to 140 beats/minute can compensate for the fall in SV in an adult. But a baby cannot increase the HR significantly, since baselines HR's are already high. So, while tachycardia is an 
important response to maintain $\mathrm{CO}$ in neonates, this response (rise in HR) is likely to be inadequate and the CO falls. ${ }^{4}$ Therapies directed to increasing SV will often, reflexively, reduce HR and improve CO.

The mean arterial pressure $=\mathrm{CO} \times \mathrm{SVR}$. Therefore, the hemodynamic variables that determine the blood pressure (BP) is combination of factors affecting $\mathrm{CO}$ and systemic vascular resistance (SVR). In a setting of sepsis, vasoconstriction to maintain $\mathrm{BP}$ is a the compensatory response to falling SV. ${ }^{4}$

In a study of 318 preterm neonates $<34$ weeks by de Waal ${ }^{10}$ et al., $4.7 \%(n=27)$ had evidence of sepsis with hemodynamic compromise. The mean RVO, LVO, and SVC flows were 430, 300, and $90 \mathrm{~mL} / \mathrm{kg} /$ minute, respectively, in stable preterm neonates $<32$ weeks' gestation with minimal respiratory support. ${ }^{10,11}$ de Waal ${ }^{10}$ et al. noted that preterm neonates with sepsis had relatively high left and right cardiac outputs and low systematic vascular resistance (SVR), after the initial volume support similar to the adult with sepsis. The mean RVO, LVO, and SVC flow at the first measurement was 555, 441, and $104 \mathrm{~mL} / \mathrm{kg} /$ minute, respectively (Fig. 1). The mean (SD) calculated SVR was $0.08(0.04) \mathrm{mm} \mathrm{Hg} / \mathrm{mL} / \mathrm{kg} /$ minute. There was a significant decrease in flow and an increase in SVR in the nonsurviving infants (Fig. 2). From the start till improvement within the sepsis episode among the survivors, there were no change in flow variables, while the SVR showed a mild increase (mean difference in SVR, $0.02 \mathrm{~mm} \mathrm{Hg} / \mathrm{mL} / \mathrm{kg} /$ minute). Mortality risk was high when RVO or LVO decreased $>50 \%$ compared to baseline. ${ }^{10}$

Similar findings have been replicated in other studies. ${ }^{12,13}$ Early in the course of pediatric septic shock, neonates have dysregulated cytokine and chemokine production. This leads to peripheral vasodilatation which is considered to be a major hemodynamic change. ${ }^{12,14}$ Therefore, persistent high-cardiac output and low SVR might benefit from increasing doses of potent vasopressors. ${ }^{10}$ Conversely, when flows or cardiac outputs are reduced, reducing vasopressor therapy and adding afterload reduction could prove beneficial (Table 1).

Deshpande et al. ${ }^{13}$ have shown that in gram-negative sepsis the mean RVO and LVO were significantly higher ( 338 and $378 \mathrm{~mL}$ / $\mathrm{kg} /$ minute, respectively), and in gram-positive sepsis they were in normal range ( 225 and $240 \mathrm{~mL} / \mathrm{kg} /$ minute, respectively). There was no significant difference in the mean ventricular outputs comparing term and preterm infants with late-onset sepsis $(p$ value $=0.422) .{ }^{13}$

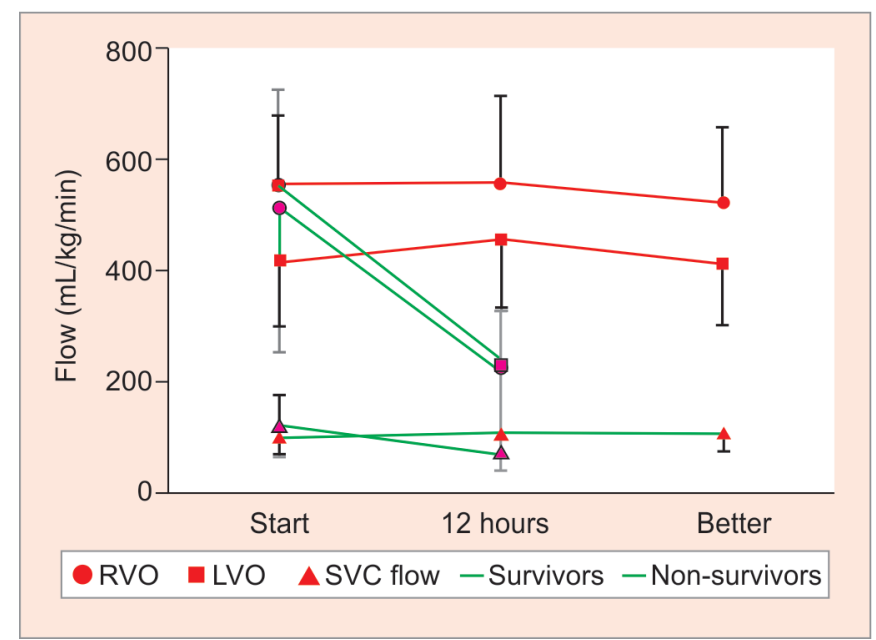

Fig. 1: CO in sepsis survivors and non-survivors ${ }^{10}$ (permission from author obtained)
The effectiveness of shock therapies can be assessed by ultrasound-derived SVC blood flow measurement in VLBW infants. The SVC flow approximates blood flow from the brain. Improved neurologic outcomes and survival is seen when the value is greater than $40 \mathrm{~mL} / \mathrm{kg} /$ minute. $^{10,15,16}$

Besides vasoregulatory failure leading to high LV output, myocardial dysfunction could coexist in neonates with septic shock leading to $\mathrm{LVO}<150 \mathrm{~mL} / \mathrm{kg} /$ minute as was noted in three neonates in the study by Saini et al. ${ }^{12}$

\section{Patency of Duct and Direction of Flow}

A significantly higher proportion of neonates with septic shock have PDA. Saini et al., ${ }^{12}$ in their study of neonates with sepsis, determined that $60 \%$ of the septic neonates had a patent duct. Infection promotes patency of PDA by increased cyclooxygenase expression and prostaglandin levels. ${ }^{17}$ The flow patterns could be left to right or bidirectional (in case of associated pulmonary hypertension) (Figs 3 and 4).

\section{Persistent Pulmonary Artery Hypertension (PPHN) of the Newborn in Sepsis}

Mohsen and $\mathrm{Amin}^{18}$ have reported that in $43.7 \%$ of cases neonatal sepsis was the cause of pulmonary hypertension, which is a second most common cause of pulmonary hypertension. In neonatal sepsis, there is a vascular response to a cytokine storm, which causes markedly elevated pulmonary vascular resistance leading to instability in pulmonary vascular tone and thus causing persistent pulmonary hypertension of the newborn (PPHN). Pulmonary vascular resistance and artery pressure can increase with sepsis-induced acidosis and hypoxia. This maintains ductus arteriosus patent that results in PPHN and persistent fetal circulation.

While a comprehensive review of pulmonary hypertension is beyond the scope of this article, a functional echo assessment in sepsis-associated pulmonary hypertension includes measurement of Peak TR velocity to determine the pulmonary pressures (Fig. 5), pattern and flow of the ductal shunt, measurements of the acceleration time in the main pulmonary artery, position of the interventricular septum, direction of the atrial shunt, and cardiac contractility. Not all the parameters would be seen in each case.

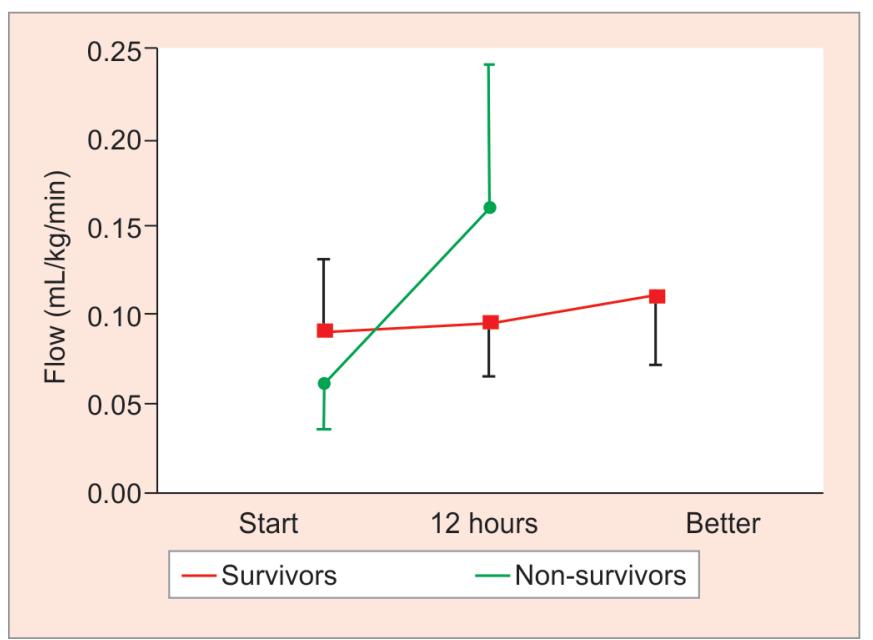

Fig. 2: Systematic vascular resistance in sepsis survivors and nonsurvivors ${ }^{10}$ (permission from author obtained) 
Table 1: Role of functional echocardiography in sepsis

\begin{tabular}{|c|c|c|c|}
\hline S. no. & Variable measured & Parameter measured & $\begin{array}{l}\text { Changes seen in } \\
\text { sepsis }\end{array}$ \\
\hline \multirow[t]{3}{*}{1.} & Cardiac flows & $\begin{array}{l}\text { Right ventricular } \\
\text { output }\end{array}$ & Increased/low \\
\hline & & $\begin{array}{l}\text { Left ventricular } \\
\text { output }\end{array}$ & Increased/low \\
\hline & & $\begin{array}{l}\text { Superior vena cava } \\
\text { flows }\end{array}$ & Low \\
\hline 2. & Ductus arteriosus & $\begin{array}{l}\text { Patency, size, flow } \\
\text { pattern, velocities }\end{array}$ & $\begin{array}{l}\text { Patent, } \\
\text { bidirectional } \\
\text { shunt seen in } \\
\text { sepsis }\end{array}$ \\
\hline \multirow[t]{4}{*}{3.} & $\begin{array}{l}\text { Pulmonary } \\
\text { hypertension }\end{array}$ & $\begin{array}{l}\text { TR jet, ductal flows } \\
\text { Dicrotic notch }\end{array}$ & $\begin{array}{l}\text { High pulmonary } \\
\text { pressures }\end{array}$ \\
\hline & & $\begin{array}{l}\text { Interventricular } \\
\text { septal position }\end{array}$ & \\
\hline & & PAAT: RVET & \\
\hline & & Diastolic function & \\
\hline 4. & IVC distensibility & $\begin{array}{l}\text { IVC diameters, } \\
\text { distensibility, } \\
\text { collapsibility }\end{array}$ & $\begin{array}{l}\text { Fluid } \\
\text { responsiveness } \\
\text { seen }\end{array}$ \\
\hline 5. & $\begin{array}{l}\text { Ventricular } \\
\text { diastolic function }\end{array}$ & $\begin{array}{l}\text { Ventricular diastolic } \\
\text { filling }(E / A)\end{array}$ & $\begin{array}{l}\text { Impaired } \\
(<0.6-0.7)\end{array}$ \\
\hline
\end{tabular}

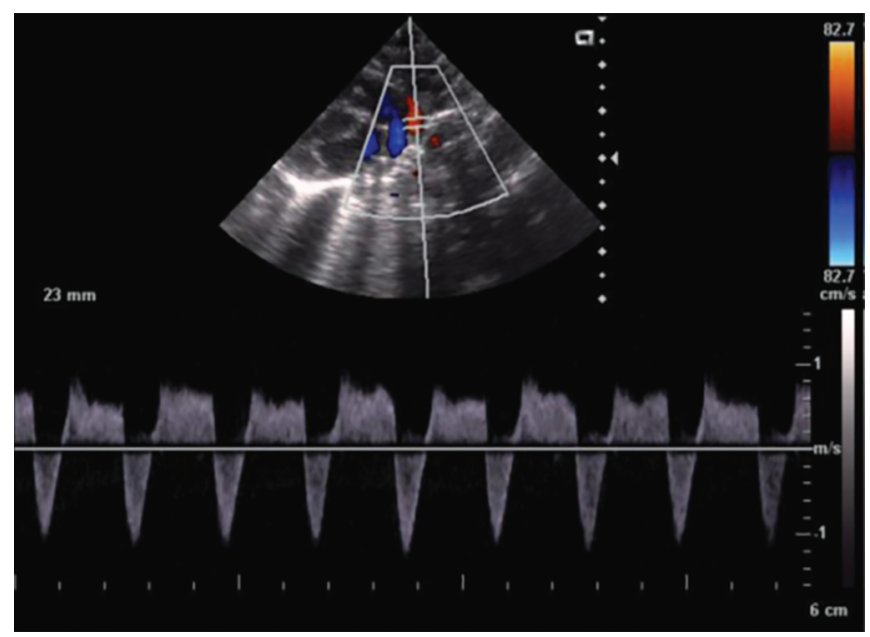

Fig. 4: Bidirectional duct in sepsis. Bidirectional shunt. As pulmonary pressures rise, pressures during cardiac systole rise $>$ than during diastole. Pulmonary pressure during systole exceeds systemic pressures but diastolic pressures are subsystemic. Hence there is a bidirectional shunt

Sepsis-associated hypoxia and acidosis cause an increase in pulmonary pressures and increased right ventricular work, which manifests as tricuspid regurgitation (TR). The TR jet is reportedly seen in $60-85 \%$ cases of PPHN. ${ }^{19}$

There is a change in RV outflow spectral Doppler pattern from a smooth round shape (Fig. 6A) to a triangular shape (Fig. 6B) in rising pulmonary artery pressure. Presence of a dicrotic notch suggests presence of pulmonary hypertension. As the pulmonary artery pressure rises, the 'Pulmonary Artery Acceleration Time (PAAT)' or "Time to Peak Velocity" gets shorter.

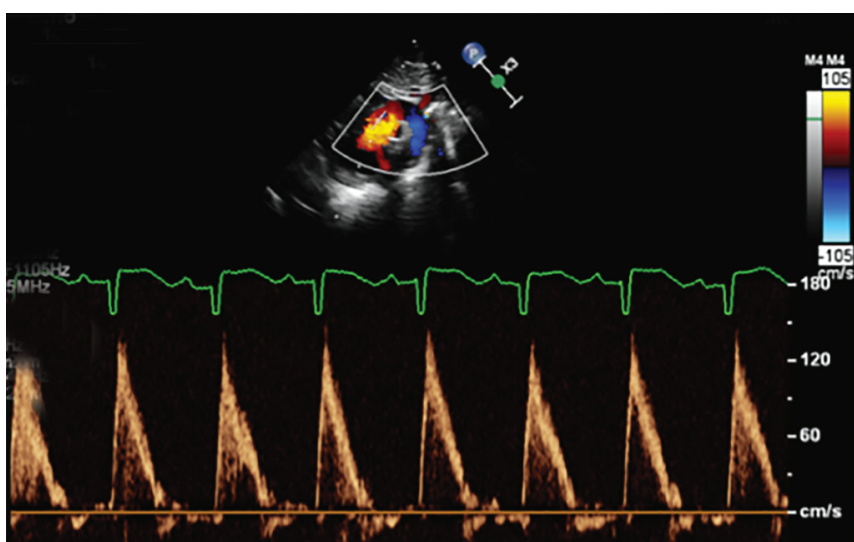

Fig. 3: Left ventricular output (LVO). LVO Measurement: Suprasternal approach to ascending aortic doppler velocity signals. Flow profile should be laminar. This image shows 'hollow' signals on the spectral display indicating non-turbulent flow. Range of LVO $=170-300 \mathrm{~mL} /$ $\mathrm{kg} /$ minute

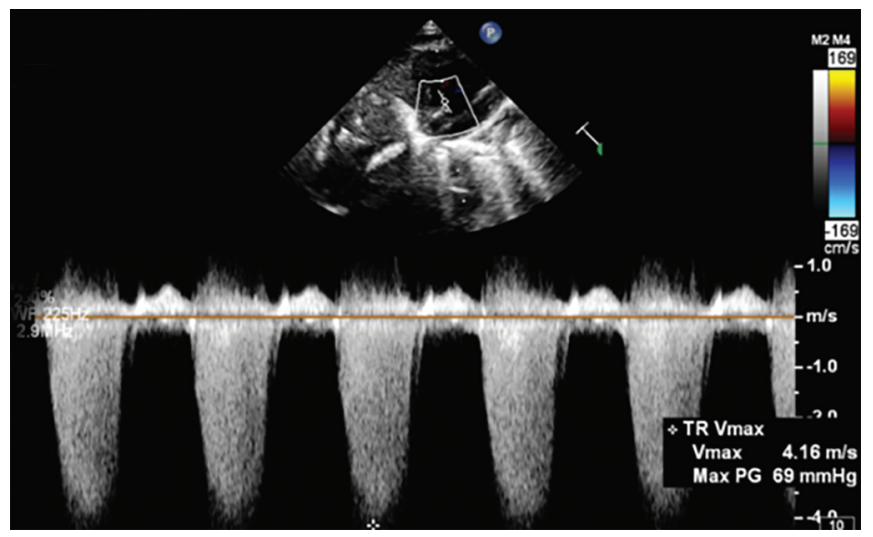

Fig. 5: Tricuspid regurgitation (TR) jet. Estimation of pulmonary artery pressures. TR jet velocity is used to derive the systolic pressure gradient between the RV and RA using Bernoulli's principle. Right ventricular systolic pressure $(\mathrm{RVSP})=$ pressure gradient + RA pressure (5-10 $\mathrm{mm} \mathrm{Hg}$ ). In a normal heart (in the absence of pulmonary stenosis), $\mathrm{RVSP}=$ pulmonary artery systolic pressure

Pulmonary hypertension can be highly predicted in neonates when PAAT is $<90 \mathrm{~ms} .{ }^{20}$ Since PAAT values are affected by heart rate, a ratio of PAAT: right ventricular ejection time is taken and values $<0.31$ are highly suggestive of $\mathrm{PH} .{ }^{20,21}$

The position of the interventricular septum may be determined by the pulmonary pressures. IVS can be flattened in pulmonary hypertension $(\mathrm{PH})$, which makes the left ventricle appear as a D-shaped structure. The patients with sepsis and pulmonary hypertension may be classified as having an "O"-shaped (no PH), "D"-shaped (flat septum, moderate PH), or "Crescentic"-shaped LV (severe $\mathrm{PH}$ ) (Figs $7 \mathrm{~A}$ and $\mathrm{B}$ ). ${ }^{15,23}$

\section{Tricuspid Annular Plane Systolic Excursion (TAPSE) (Fig. 8)}

The systolic displacement of the tricuspid annulus toward the RV apex along the longitudinal axis can be measured by a TAPSe which is a sensitive measure of RV systolic function. ${ }^{19,20}$ The greater the descent of the basal annulus in systole, the better the RV systolic function. In term neonates, the mean value is $0.91 \mathrm{~cm}(0.68-1.150){ }^{19}$ The TAPSE values vary depending on the gestation age and weight of the neonate. 

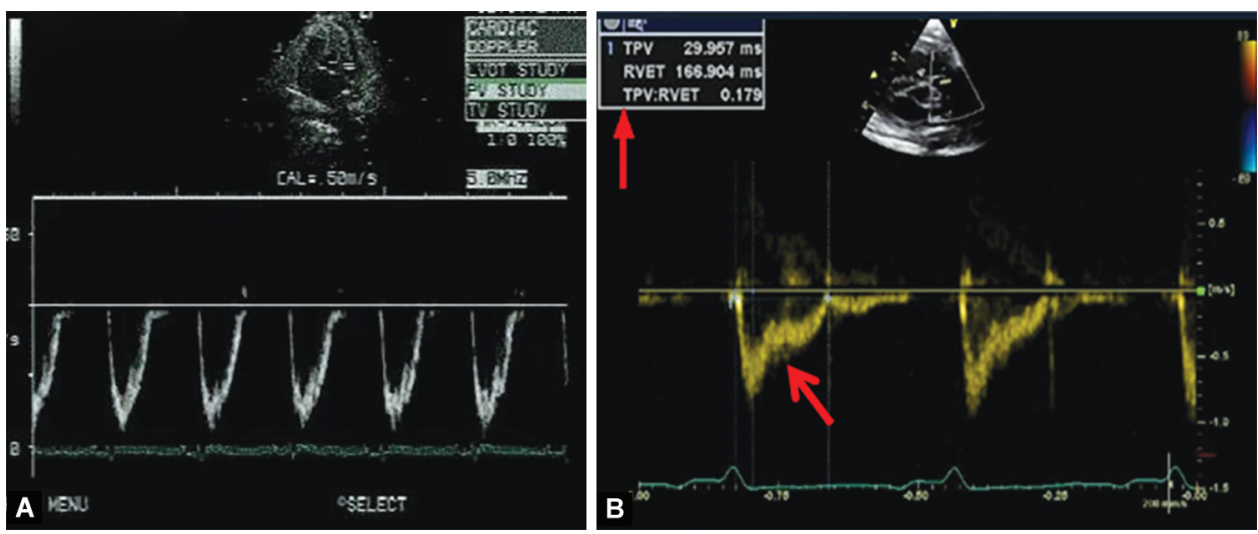

Figs 6A and B: (A) RV outflow doppler: smooth laminar flow; (B) Presence of dicrotic notch
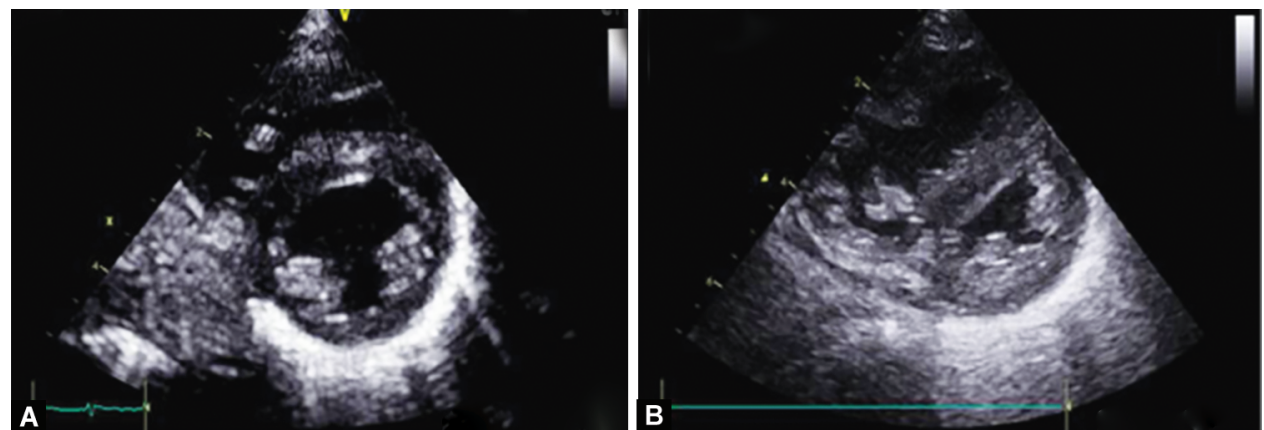

Figs 7A and B: (A) 'O' shaped IVS; (B) 'D' shaped IVS
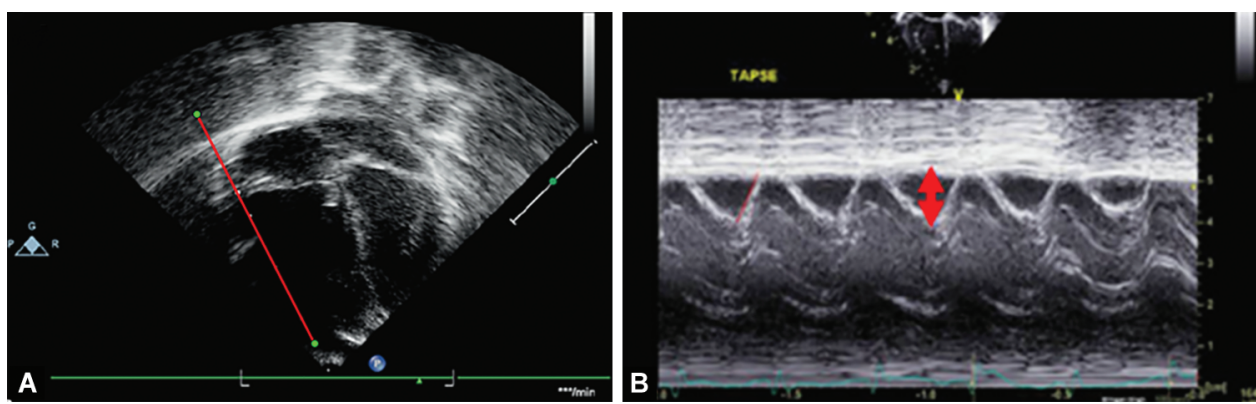

Figs 8A and B: (A)TAPSE measurement—-measure along free wall of tricuspid valve; (B) TAPSE measurement—'M Mode' excursion distance measured

Table 2: Inferior vena cava (IVC) diameter and variations in sepsis ${ }^{21}$

\begin{tabular}{lll}
\hline IVC diameter & IVC respiratory variation & Clinical status \\
\hline$<8 \mathrm{~mm}$ & $>50 \%$ collapse & Fluid responsive \\
$<8 \mathrm{~mm}$ & $<50 \%$ collapse & May give fluids \\
$>8 \mathrm{~mm}$ & $<50 \%$ collapse & Normal \\
$>8 \mathrm{~mm}$ & No inspiratory collapse & $\begin{array}{l}\text { High fluid status (RV } \\
\text { failure, high pulmonary } \\
\text { pressures, hypervolemia) }\end{array}$ \\
\hline
\end{tabular}

In neonates with fluid-refractory shock and PPHN, the pulmonary artery pressures can be reduced by therapies directing at reversal of right ventricular failure. ${ }^{4}$

\section{Inferior Vena Cava (IVC) Distensibility Variations (Table 2)}

One of the challenges in management of sepsis is to know which neonate will respond to a fluid challenge. A quantitative method is to measure the IVC diameter and determine the variation in diameter with respiration. In sepsis, this variation during respiration can assist in diagnosis of hypovolemia and guide fluid therapy.

The chest volume expands during inhalation as the dome of the diaphragm is lowered (flattened). This increases abdominal pressure resulting in compression of the wall of the inferior vena cava, thus creating the smaller dimension of the vessel. This is called the "inspiratory collapse."

There are two measures that are taken into consideration: the IVC collapsibility index and the IVC distensibility index (Fig. 9). ${ }^{20}$

IVC Collapsibility Index $=D_{\max }-D_{\min } / D_{\max } \times 100 \%(D=$ diameter of IVC $)$

$$
\text { IVC Distensibility Index }=D_{\max }-D_{\min } / D_{\min } \times 100 \%
$$

While an IVC Collapsibility index $>55 \%$ is predictive of fluid responsiveness, an IVC distensibility index $>18 \%$ is predictive of fluid responsiveness. However, these values need to be interpreted 


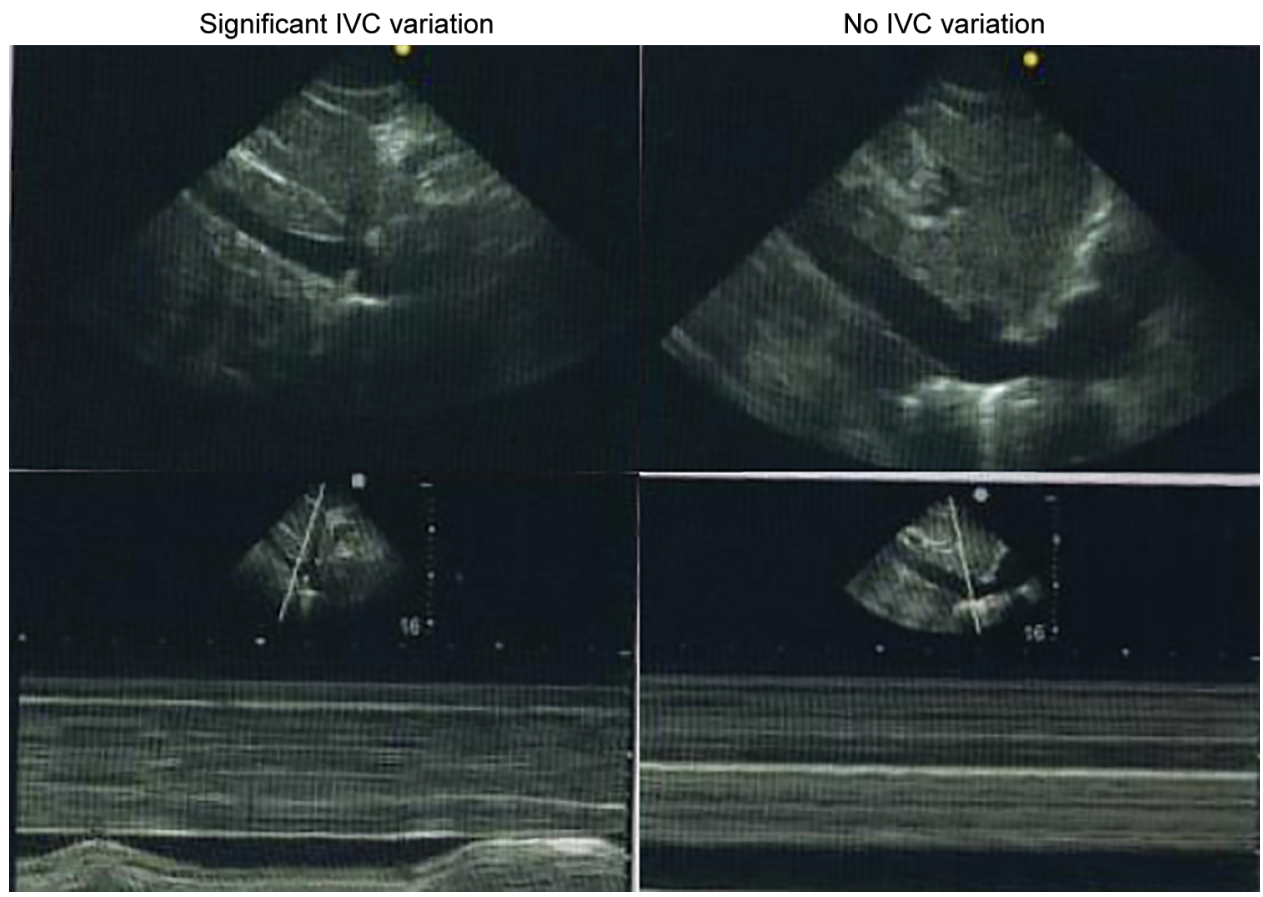

Fig. 9: Inferior vena cava status. ${ }^{21}$ Key findings in favor of hypovolemia on 2D imaging. LV and RV of small dimensions and hyperkinetic. Small LV end-systolic and end-diastolic areas. Increased LV ejection fraction (>70\%). Small IVC diameter with wide respiratory variation
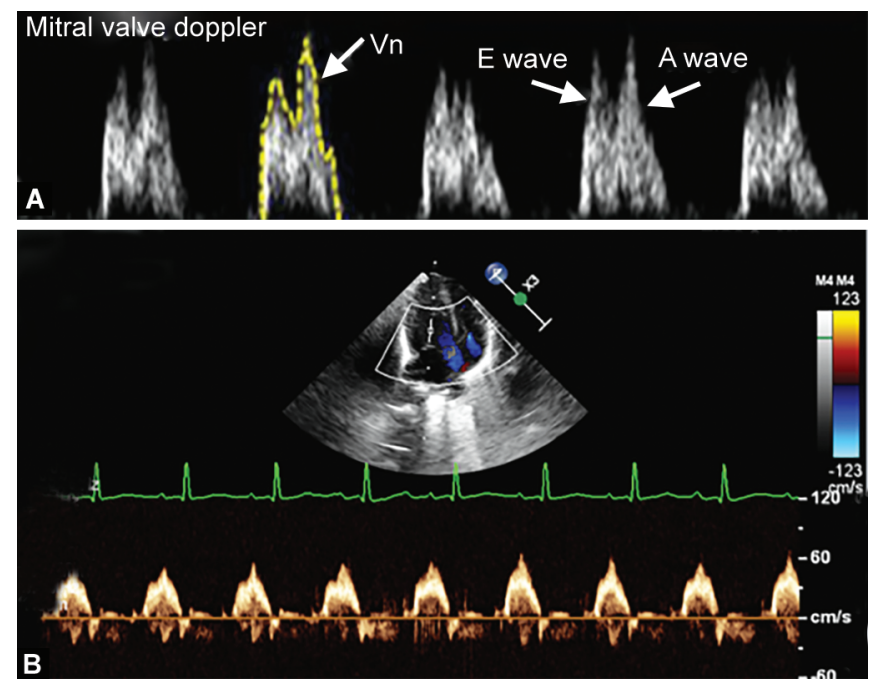

Figs $10 \mathrm{~A}$ and $\mathrm{B}$ : Assessment of diastolic function (E/A ratio). Diastolic function: 'E wave': phase of passive ventricular filling. 'A wave': atrial contraction phase. Normal 1:1 ratio. Diastolic filling abnormality: E/A $<0.6-0.7: 1$ (Fig. 7B)

with caution, since studies have validated these in self-breathing adults. $^{20}$

\section{Impaired Ventricular Diastolic Function}

Babies with neonatal sepsis may also have an impaired diastolic filling although this may not be a universally recognized feature. Relaxation of the myocardium is an active process. Transmitral flow occurs in two phases: majority of the filling occurs ('E' wave) in an early phase of passive flow across $\mathrm{AV}$ valve. The remaining third of the venous return to the ventricle is delivered (' $A$ ' wave) in the late atrial contraction phase. The comparision of maximum $E$ and $A$ wave velocities are done as ratios.
The majority of filling occurs during the atrial phase in diastolic dysfunction, as the passive early flow across mitral valve is prevented by the stiff ventricular wall. This biphasic pattern of transmitral flow can be examined by pulsed wave Doppler. In normal children, E filling is greater than A. In neonatal period, mean normal ratio is 1:1 in preterm and 1.1:1 in full-term neonates. A ratio of $<0.6: 1$ in preterm and $<0.7: 1$ in term babies is highly suggestive of diastolic filling abnormality (Fig. 10). ${ }^{22}$

In a study on LV functions in septic and nonseptic neonates $(n=60)$, Tomerak et al. ${ }^{23}$ noted significantly lower E/A ratio in the septic than in the nonseptic newborns, suggesting LV diastolic dysfunction. No difference was noticed in the LV systolic function between septic and nonseptic neonates. Impaired diastolic function is also seen as a characteristic feature in the immature fetal and preterm myocardium, and therefore, this may not be diagnostic in neonatal sepsis.

\section{Role of Cranial Ultrasound in Sepsis ${ }^{24,25}$}

The common manifestation of late-onset neonatal sepsis is neonatal bacterial meningitis. The assessment of infants with clinical suspicion of bacterial meningitis, and follow-up of its complications can be done by cranial ultrasonography (CUS). The intraventricular contents, especially debris and intraventricular septations, can be evaluated by CUS. It is superior to computed tomography and magnetic resonance imaging as an imaging modality due to absent need for sedation and lack of ionizing radiation, speed of imaging, low cost, and easy portability.

Infection of cerebrospinal fluid (CSF) and subsequently ventriculitis result from seeding of choroid plexus caused by bacteremia. Pia and arachnoid mater including the vessels traversing the subarachnoid space are also infected. The permeability of membrane and vessel wall is increased by the inflammatory response and thus causing accumulation of inflammatory exudates. 
The common sonographic findings include (Table 3):

- Echogenic sulcus: it is the most common finding and seen as the earliest finding. Sulcal thickness should not normally be $>2$ $\mathrm{mm}$ as this includes pia and arachnoid mater. Accumulation of inflammatory exudates can result in widening and increased echogenicity (Fig. 11).

- Ventriculomegaly occurs due to increased production and decreased CSF absorption during the acute phase of bacterial meningitis (Fig. 12).

- Ventriculitis: it is identified as increased thickness, irregularity, and increased echogenicity of the ependyma. This occurs because ventricles and choroid plexus act as reservoirs of infection. This can cause it to harbor bacteria, but the lumbar puncture can yield sterile cultures. Inflammatory exudate may undergo organization into strands and fibrous septae in longstanding chronic cases (Figs 13A and B).

- Abnormal resistive index (RI) (Fig. 14): There is a paucity of literature explaining the effect of sepsis on cerebral blood flow through early cerebrovascular alteration. In early sepsis, cerebral vasodilation occurs because of production of cytokines and interleukins, thus increasing cerebral blood flow causing decreased RI. ${ }^{26}$ However, decreased cerebral blood flow with increased RI can be caused by sepsis by unknown mechanisms, likely due to vasoconstriction of cerebral resistance arterioles. ${ }^{27}$ Decreased compliance of the

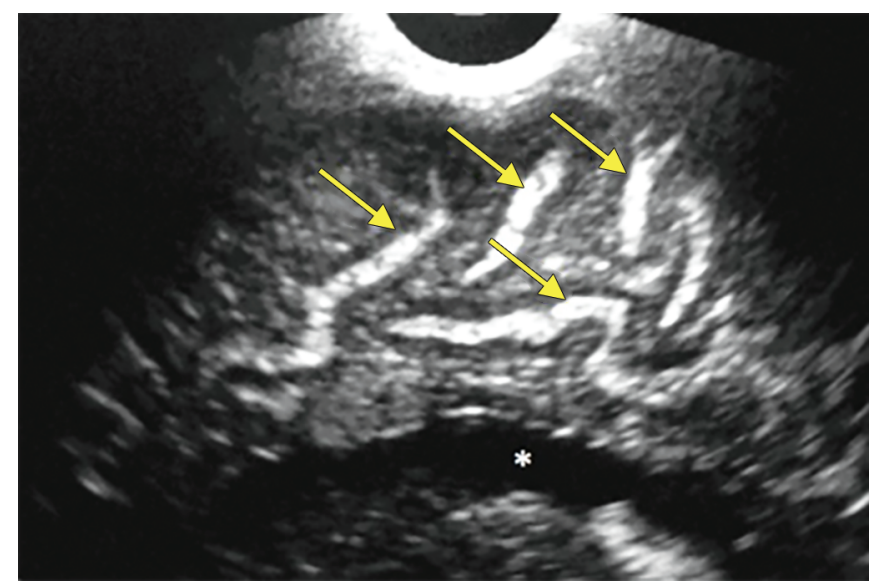

Fig. 11: Widened echogenic cerebral sulci

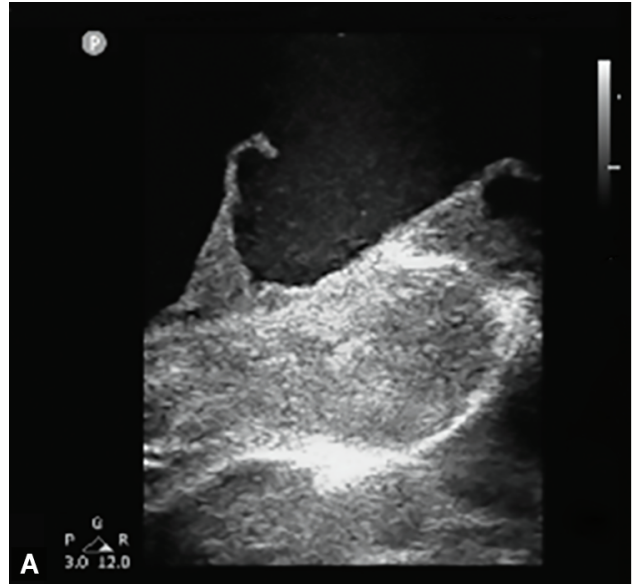

Figs $13 \mathrm{~A}$ and $\mathrm{B}$ : Coronal view of $A F$ with fibrous strands (A) and septae (B) suggesting ventriculitis
Table 3: Sonographic findings in neonatal bacterial meningitis ${ }^{24}$

\begin{tabular}{lll}
\hline Findings & Description & Significance \\
\hline Echogenic sulci & Sulcal thickness $>2 \mathrm{~mm}$ & Often transient \\
Ventriculitis & Echogenic debris & Causes lack of \\
& within ventricular & response to \\
& cavity; late stages: & antibiotics \\
& septae formation, & Choroid plexus \\
& compartmentalization, & infections cause \\
& intraventricular cysts; & recurrent infections \\
& choroid plexitis: & Requires long- \\
& $\begin{array}{l}\text { echogenicity and } \\
\text { irregularity of choroid }\end{array}$ & term follow-up for \\
& plexus & hydrocephalus \\
Ventriculomegaly/ & Lateral ventricle width & Acute stage: due \\
hydrocephalus & $>11$ mm at level of & to CSF production \\
& body & and decreased \\
& & absorption \\
& Periventricular hy- & Chronic stage: \\
& poechogenicity due to & fibrotic obstruction \\
& periventricular ooze & Parenchymal atrophy \\
& Intraventricular & Long-term \\
& hemorrhage: & neurodevelopment \\
& grade II-III with/with- & may be affected \\
& out post-hemorrhagic & \\
& ventricular dilatation & \\
& Echodensities in & \\
thalamus, basal ganglia & \\
\hline Miscellaneous & & \\
& & \\
& & \\
& & \\
& & \\
& & \\
& & \\
& &
\end{tabular}

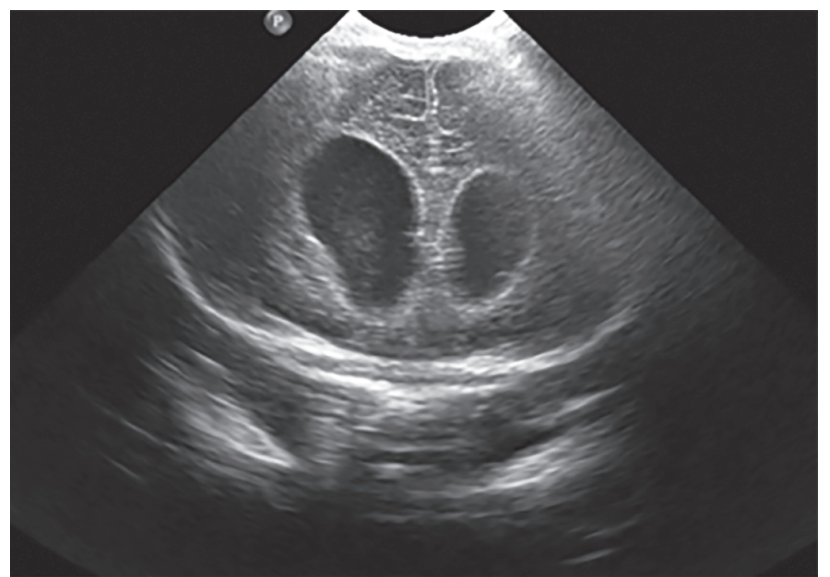

Fig. 12: Dilated frontal horns of lateral ventricle

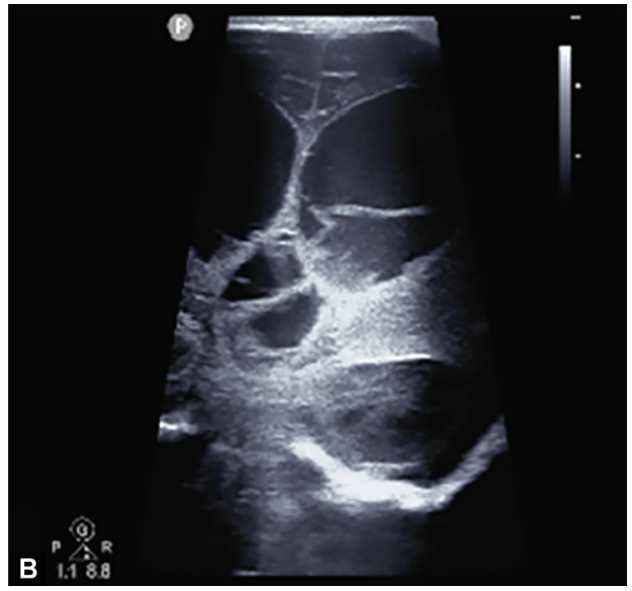


vascular bed results in increased $\mathrm{RI}$, and it is associated with poor neurological outcomes.

- Brain abscess: This is a rarely reported complication in neonates (Fig. 15). Clinical data along with serial CUS examinations may differentiate between an early phase abscess and an ischemic process, thus helping in making a correct diagnosis.

\section{Role of Lung Ultrasound (LUS) in Detection of Infective Pathologies}

The two infective pathologies, that LUS would be useful in, are lung consolidation and pleural effusions. In pediatric age-group, lung consolidation can be accurately diagnosed by LUS when compared to chest radiography in pediatric age-group, and this is backed by a strong evidence. ${ }^{29}$

\section{Lung Consolidation}

A positive LUS can confirm a clinical suspicion of pneumonia and can exclude the need for CXR. If the conolidation does not reach the pleura, the LUS may not detect the consolidation. The extension to the pleura may occur more frequently as the

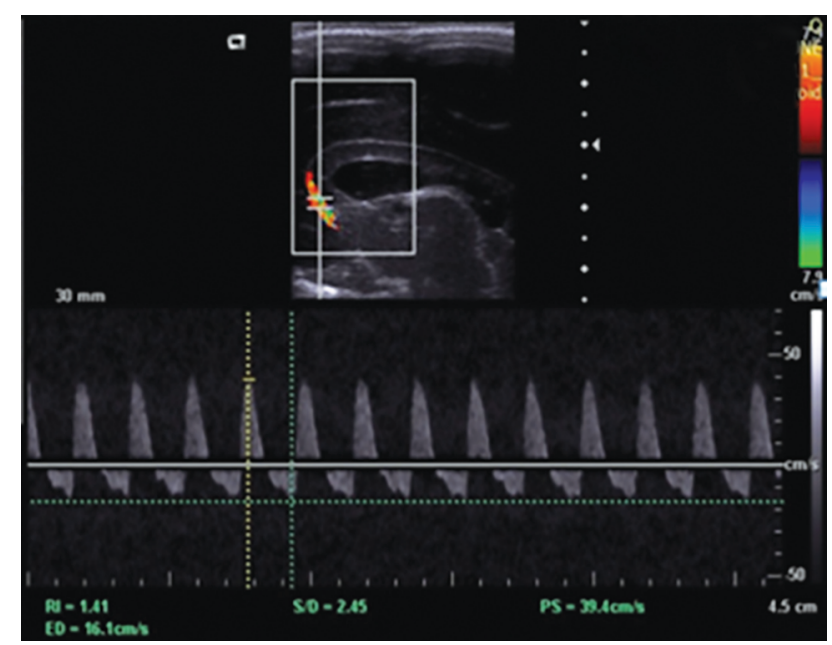

Fig. 14: High RI with reversal of diastolic flow in anterior cerebral artery

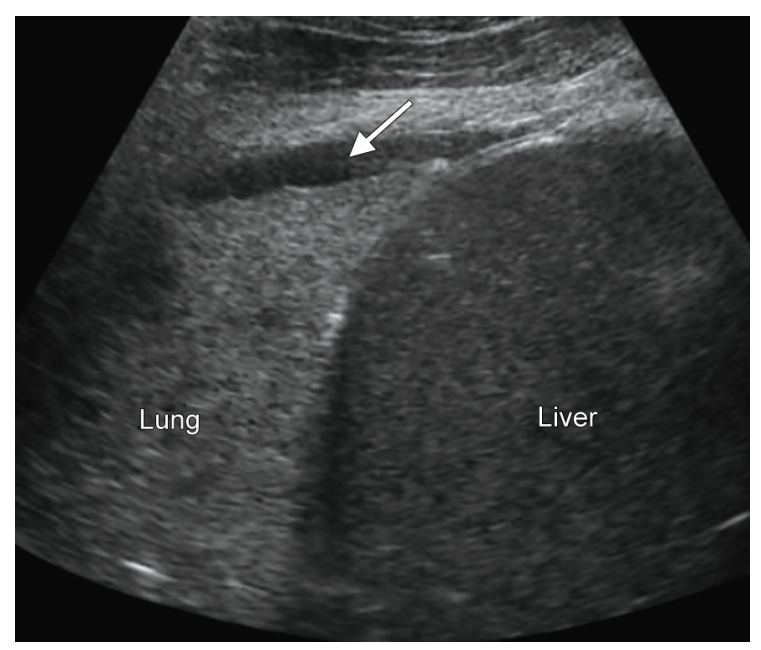

Fig. 16: Hepatization of the subpleural lung tissue newborn lung mass is smaller. ${ }^{29}$ The echogenicity and echotexture of the consolidated airless lung are similar to liver, hence it appears as hepatization (Fig. 16). The air bronchogram visible on standard chest radiographs appears as multiple bright dot-like and branching linear structures in the solid-appearing area of echogenicity that represents air in the bronchi (Fig. 17). ${ }^{30}$

The "Shred Sign" is a sonographic sign seen in neonates with lung consolidation (Fig. 18). The area of contact between the consolidated lung and the deeper aerated lung appears shredded and irregular. In massive consolidation, the sign is not well seen, since it is more difficult to visualize very deep structures.

\section{Pleural Effusion}

It is visualized as Quad Sign, which is an anechoic space between the parietal and visceral pleura (Fig. 19). The nature of the effusion can be diagnosed by lung ultrasound. It is considered as exudate (Fig. 20) or hemothorax when there is visualization of internal echoes, either of mobile particles or septa. However, when there is an anechoic effusion (Fig. 20), the transudate and exudate can be differentiated by use of thoracentesis or alternatively can be evaluated in the clinical context.

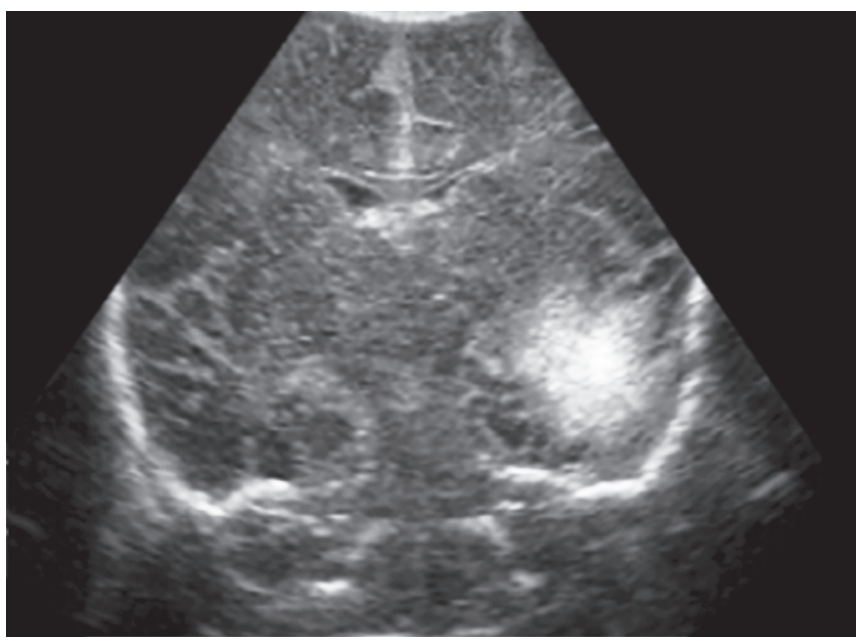

Fig. 15: Coronal view at the ant horn level-hyperechoic area in left temporal lobe-suggestive of brain abscess ${ }^{28}$

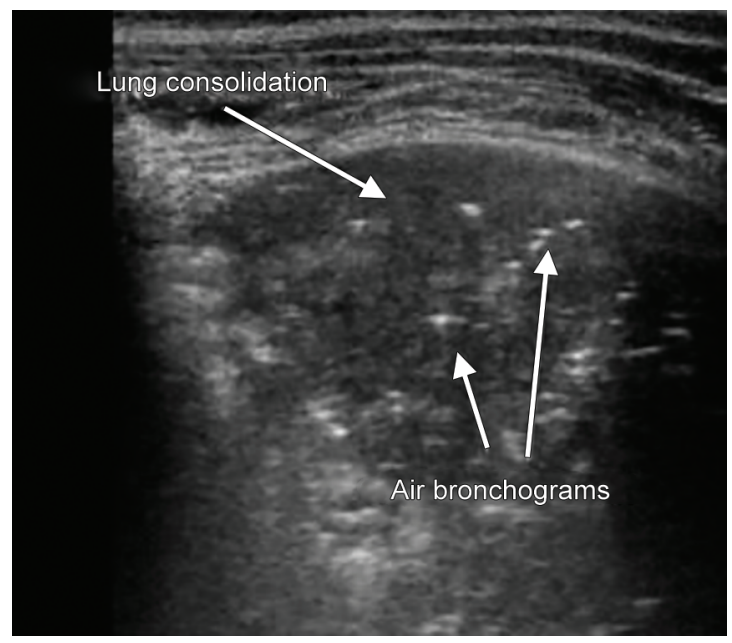

Fig. 17: Multiple bright dot-like, branching linear structures, represent air in bronchi 

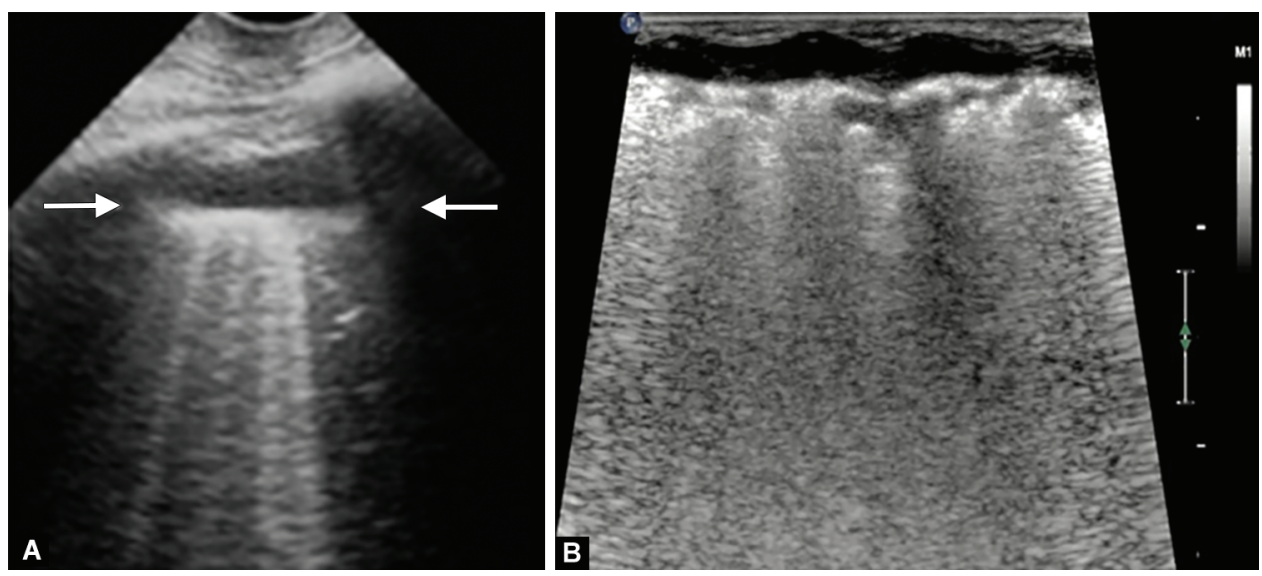

Figs 18A and B: Shred sign: Specific to lung consolidation, white arrows indicate pleural line. (A) Pleural line intact; (B) Pleural line is shredded
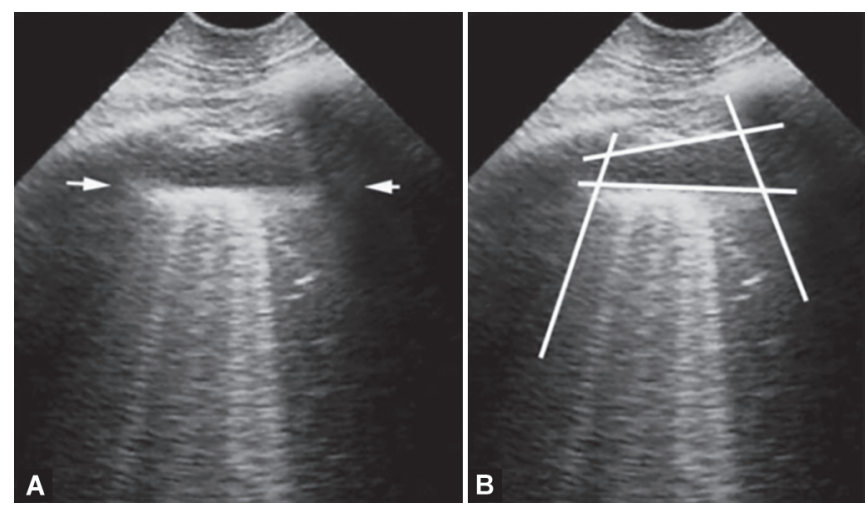

Figs 19A and B: Quad sign. (Minimum pleural effusion) Quadrilateral space between the parietal and the visceral pleura (indicated by white arrows in (A), and the shadow of rib margins laterally

\section{Role of US in Necrotizing Enterocolitis (NEC) ${ }^{31,32}$}

The physiology and tissue architecture of the gut is disrupted by a severe inflammatory condition of the bowel in pretems called as NEC. Abdominal X-rays have remained the gold standard so far, but there is an increasing role for abdominal US in diagnosing NEC. The static physical characteristics, such as bowel wall thickness, wall diameter, dilatation, and echogenicity, as well as dynamic characteristics of peristalsis and perfusion, can be determined by US imaging in NEC. Since preterm and term neonates are small, and have thin abdominal walls, bowel US is easy to perform.

\section{Physical Characteristics}

These include bowel wall thickness, wall diameter, dilatation, and echogenicity. It is described that the bowel wall thickness in a normal term neonate is $1.1-2.6 \mathrm{~mm}$, while it is estimated to be $1.2-2$ $\mathrm{mm}$ in preterms babies. It is likely to be NEC when the bowel wall thickness is $>2 \mathrm{~mm}$; abnormal thinning with a thickness of $<1.0 \mathrm{~mm}$ results from ischemia or necrosis. ${ }^{33}$

\section{Blood Flow}

Normal bowel wall is smooth with peristalsis, and it is said to normally perfused when there are 1-9 color Doppler signal dots per $\mathrm{cm}^{2}$ (mean 3.8). In early NEC, there is an increased bowel perfusion that can appear with different patterns such as ringshape, Y-shaped, and zebra-shaped (Fig. 21).

\section{Intramural Gas}

This is seen as highly echogenic dots in the bowel wall, called as "circle sign,"as it may involve the whole circumference (Fig. 22). The clinical severity of NEC cannot be determined by the amount of intramural gas present, and its disappearance does not correlate with clinical improvement. ${ }^{34}$ BUS detects portal venous gas better than radiographs due to the high echogenic signal air produced. ${ }^{35}$

In a study by Silva ${ }^{36}$ et al., there was a sensitivity of 0.82 and a specificity of 0.78 for poor outcome when three of the seven USG features (portal venous gas, intramural gas, increased wall echogenicity, bowel wall thickening or thinning, absent perfusion, free echogenic fluid) were present. The early diagnosis and monitoring of patients with NEC can be done with bowel sonography.

Ultrasound imaging has a role in diagnosis of deep seated sites of infection such as liver abscesses, perinephric collection of fluid, and suprapubic urinary bladder urine collection for culture.

\section{Summary-Role of Point-of-care Ultrasound in Neonatal Sepsis}

\begin{tabular}{|c|c|c|}
\hline S. No. & Imaging modality & Variable measured \\
\hline \multirow[t]{5}{*}{1.} & $\begin{array}{l}\text { Functional } \\
\text { echocardiography }\end{array}$ & $\begin{array}{l}\text { Cardiac flows_-right, left ventricles } \\
\text { and SVC flows }\end{array}$ \\
\hline & & Presence of ductus arteriosus \\
\hline & & $\begin{array}{l}\text { Presence of pulmonary } \\
\text { hypertension }\end{array}$ \\
\hline & & IVC distensibility. collapsibility \\
\hline & & Ventricular diastolic function \\
\hline \multirow[t]{8}{*}{2.} & Cranial ultrasound & Echogenic sulci \\
\hline & & Ventriculitis \\
\hline & & Hydrocephalus/ventriculomegaly \\
\hline & & Intra-ventricular hemorrhage \\
\hline & & $\begin{array}{l}\text { Post-ventricular hemorrhagic } \\
\text { dilatation }\end{array}$ \\
\hline & & Echodensities in basal ganglia \\
\hline & & Abnormal resistive index \\
\hline & & Brain abscess \\
\hline \multirow[t]{2}{*}{3.} & Lung ultrasound & Lung consolidation \\
\hline & & Pleural effusion \\
\hline
\end{tabular}




\begin{tabular}{lll} 
Contd... & & \\
\hline S. No. & Imaging modality & Variable measured \\
\hline 4. & Bowel imaging & Bowel wall thickness, diameter \\
& & Ileus \\
& Echogenicities \\
& Blood flows \\
& Intramural gas \\
& Ascites \\
\hline
\end{tabular}

\section{Key Message}

- Point-of-care ultrasound imaging has become a useful tool in the hands of the clinician to determine the site of infection, the progress of sepsis, and prognosis/outcomes of neonates with sepsis.

- Ultrasound imaging can determine cardiac hemodynamics and aid the clinician in appropriate use of inotropes and vasopressors.
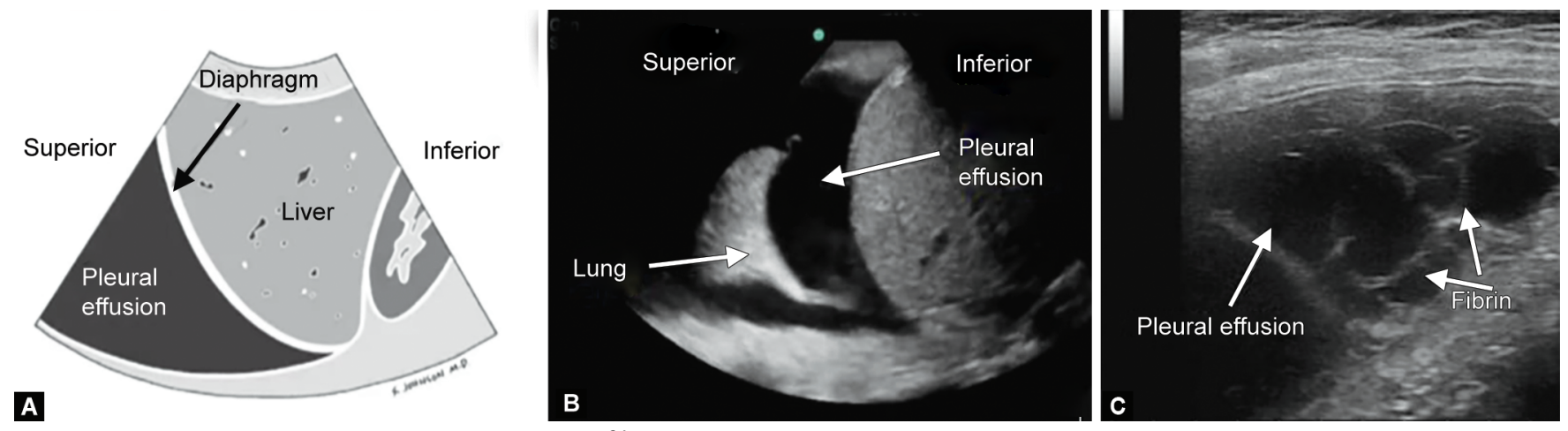

Figs 20A to C: Pleural effusion from the subcostal view: ${ }^{24}$ (A) Normal view; (B) Large pleural effusion; (C) Fibrous septae
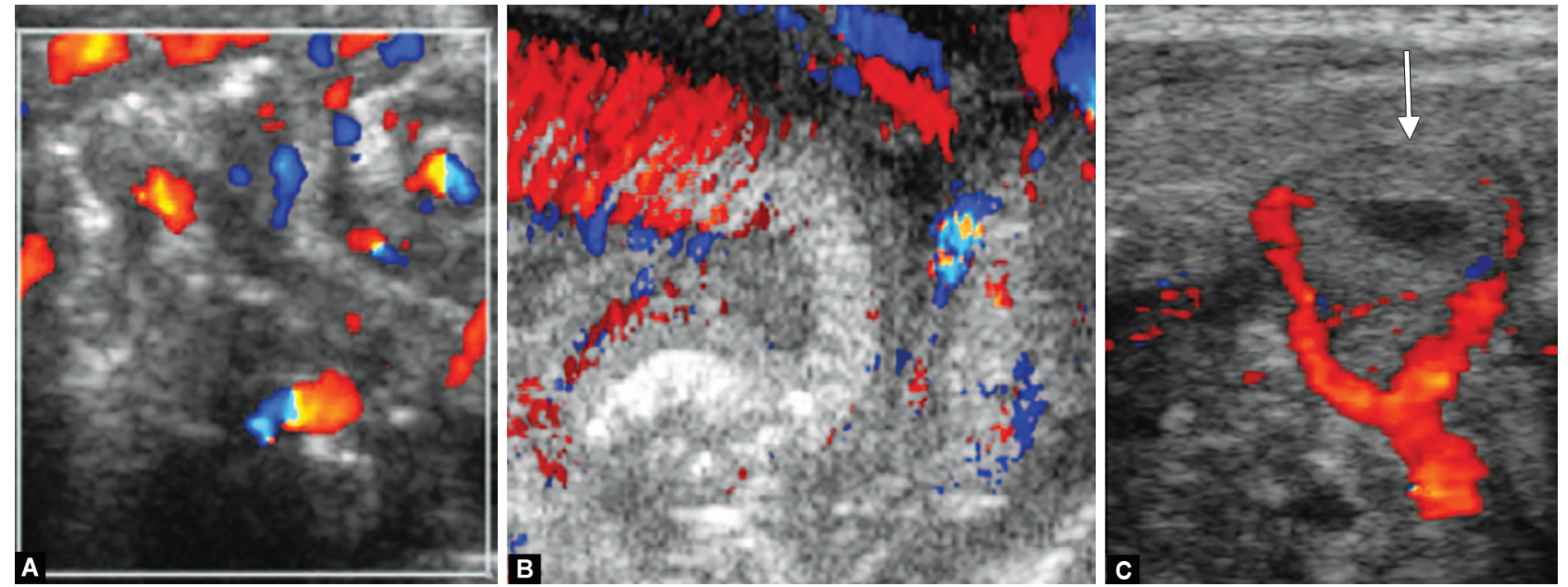

Figs 21A to C: Bowel wall perfusion—normal perfusion and hyperemia: (A) Normal perfusion; (B) Zebra pattern; (C) Y-shaped pattern
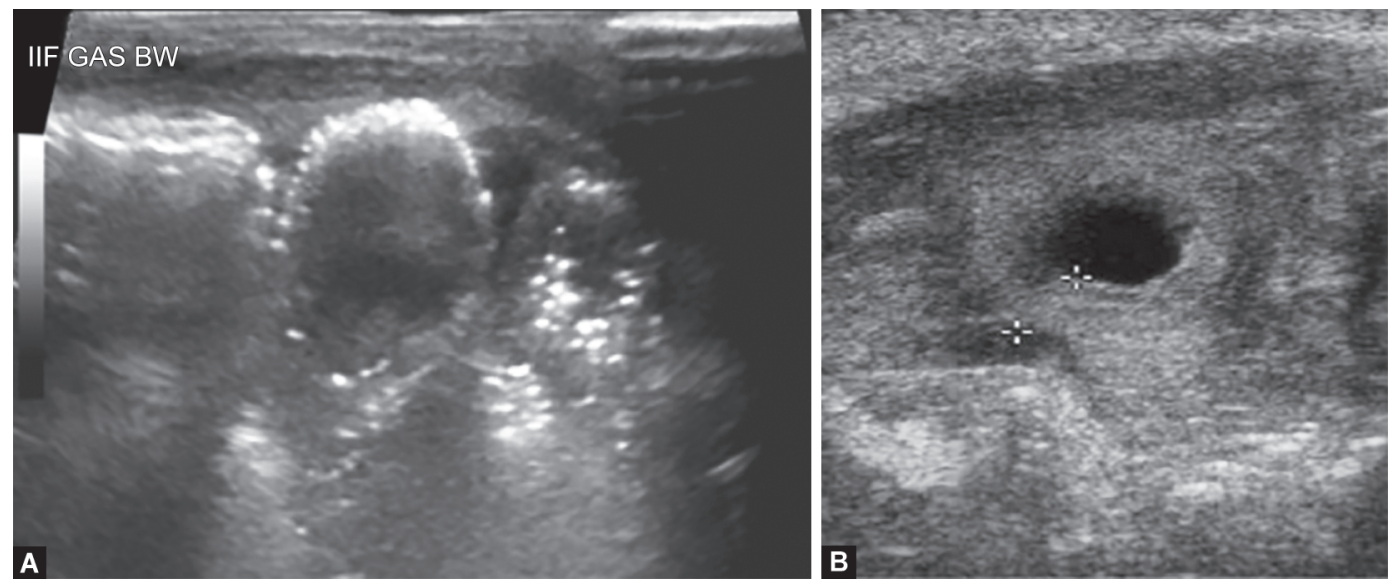

Figs 22A and B: (A) Echo shadows in the bowel wall; (B) Bowel wall edema-pneumatosis intestinalis 
- Lung ultrasound has a significant role in urgent bedside evaluation of the neonatal lung disorders such as consolidation and pleural effusions.

- Bowel sonography can be helpful for the early diagnosis and monitoring of patients with NEC.

\section{References}

1. Liu L, Oza S, Hogan D, et al. Global, regional, and national causes of child mortality in 2000-2013, with projections to inform post-2015 priorities: an updated systematic analysis. Lancet 2015;385(9966):430-440. DOI: 10.1016/S0140-6736(14)61698-6.

2. Stoll BJ, Gordon T, Korones SB, et al. Late-onset sepsis in very low birth weight neonates: a report from the national institute of child health and human development neonatal research network. J Pediatr 1996;129(1):63-71. DOI: 10.1016/S0022-3476(96)70191-9.

3. Stoll BJ, Hansen NI, Adams-Chapman I, et al. Neurodevelopmental and growth impairment among extremely low-birth-weight infants with neonatal infection. JAMA 2004;292(19):2357-2365. DOI: 10.1001/ jama.292.19.2357.

4. Al Davis, Carcillo JA, Aneja RK, et al. American College of Critical Care Medicine clinical practice parameters for hemodynamic support of pediatric and neonatal septic shock. Crit Care Med 2017;45(6): 1061-1093. DOI: 10.1097/CCM.0000000000002425.

5. Aneja RK, Carcillo JA. Differences between adult and pediatric septic shock. Minerva Anestesiol 2011;77(10):986-992.

6. Hunter JD, Doddi M. Sepsis and the heart. Br J Anaesth 2010;104(1):311. DOI: 10.1093/bja/aep339.

7. Fernandez EF, Watterberg KL. Relative adrenal insufficiency in the preterm and term infant. J Perinatol 2009;29(Suppl 2):S44-S49. DOI: 10.1038/jp.2009.24.

8. Kluckow M, Seril, Evans N. Functional echocardiography: an emerging clinical tool for the neonatologist. J Pediatr 2007;150(2):125-133. DOI: 10.1016/j.jpeds.2006.10.056.

9. Evans N. Assessment and support of the preterm circulation. Early Hum Dev 2006;82(12):803-810. DOI: 10.1016/j.earlhumdev.2006.09.020.

10. de Waal K, Evans N. Hemodynamics in preterm infants with late-onset sepsis. J Pediatr 2010;156(6):918-922. DOI: 10.1016/j. jpeds.2009.12.026.

11. Sloot SC, de Waal KA, van der Lee JH, et al. Central blood flow measurements in stable preterm infants after the transitional period. Arch Dis Child Fetal Neonatal Ed 2010;95(5):F369-F372. DOI: 10.1136/ adc.2009.169169.

12. Saini $S$, Kumar P, Kumar R. Hemodynamic changes in preterm neonates with septic shock: a prospective observational study. Pediatr Crit Care Med 2014;15(5):443-450. DOI: 10.1097/PCC.0000000000000115.

13. Deshpande S, Suryawanshi P, Chaudhary N, et al. Cardiac output in late onset neonatal sepsis. J Clin Diagn Res 2017;11(11):SC25-SC28. DOI: 10.7860/JCDR/2017/30312.10871.

14. Landry DW, Oliver JA. The pathogenesis of vasodilatory shock. N Engl J Med 2001;345(8):588-595. DOI: 10.1056/NEJMra002709.

15. Kluckow M, Evans N. Low superior vena cava flow and intraventricular haemorrhage in preterm infants. Arch Dis Child Fetal Neonatal Ed 2000;82(3):F188-F194. DOI: 10.1136/fn.82.3.F188.

16. Kluckow M, Evans N. Low systemic blood flow in the preterm infant. Semin Neonatol 2001;6(1):75-84. DOI: 10.1053/siny.2000.0035.

17. Kim ES, Kim EK, Choi CW, et al. Intrauterine inflammation as a risk factor for persistent ductus arteriosus patency after cyclooxygenase inhibition in extremely low birth weight infants. J Pediatr 2010;157(5):745-750.e1. DOI: 10.1016/j.jpeds.2010.05.020.
18. Abdel Mohsen AH, Amin AS. Risk factors and outcomes of persistent pulmonary hypertension of the newborn in neonatal intensive care unit of Al-Minya University Hospital in Egypt. J Clin Neonatol 2013;2(2):78-82. DOI: 10.4103/2249-4847.116406.

19. Kirkpatrick EC. Echocardiography in pediatric pulmonary hypertension. pediatric Resp reviews. Paediatr Respir Rev 2013;14(3):157-164.

20. Singh $Y$. Echocardiographic evaluation of hemodynamics in neonates and children. Front Pediatr 2017;5:201. DOI: 10.3389/fped.2017. 00201.

21. Suryawanshi P, Parikh T, Sahni M, et al. Point of Care Neonatal Ultrasound and Neonatal Cardiology. 2nd edn, 2016.

22. Wyllie JP. Ventricular function. In: Skinner J, Alverson D, Hunter S, ed. Eechocardiography for the Neonatologist. Churchill Livingstone; 2000.

23. Tomerak RH, El-Badawy AA, Hussein G, et al. Echocardiogram done early in neonatal sepsis: What does it add? J Investig Med 2012;60(4):680-684. DOI: 10.2310/JIM.0b013e318249fc95.

24. Gupta N, Grover H, Bansal I, et al. Neonatal cranial sonography: ultrasound findings in neonatal meningitis-a pictorial review. Quant Imaging Med Surg 2017;7(1):123-131. DOI: 10.21037/qims.2017.02.01.

25. Claessens LC, Zonnenberg IA, van den Dungen FAM, et al. Cerebral ultrasound abnormalities in preterm infants caused by lateonset sepsis. PLoS One 2017;12(3):e0173227. DOI: 10.1371/journal. pone. 0173227.

26. Hashem RH, Abdalla YE, Mansi YA, et al. Transcranial Doppler evaluation of cerebral hemodynamic alteration in preterms with early onset neonatal sepsis. Artery Res 2017;19(C):83-90. DOI: 10.1016/j. artres.2017.06.004.

27. Singh YR, Suryawanshi P. Reversal of end diastolic flow in anterior cerebral artery in late onset neonatal sepsis. J Neonatol 2018; 32(2-3):71-73. DOI: 10.1177/0973217918795009.

28. Anca IA, Jugulete $G$, Brezan F, et al. Trans fontanelar ultrasound diagnosis of brain abscesses in two neonates. Med Ultrason 2009;11(4):77-82.

29. Volpicelli G, Elbarbary M, Blaivas M, et al. International liaison committee on lung ultrasound (ILC-LUS) for international consensus conference on lung ultrasound (ICC-LUS). international evidencebased recommendations for point of-care lung ultrasound. Intensive Care Med 2012;38:577-591. DOI: 10.1007/s00134-012-2513-4.

30. Rath C, Suryawanshi P. Point of care lung ultrasound in neonatology. J Neonatol 2018;32(1):27-37. DOI: 10.1177/0973217918766994.

31. Epelman M, Daneman A, Navarro OM, et al. Necrotizing enterocolitis: review of state-of the- art imaging findings with pathologic correlation. Radiographics 2007;27(2):285-305. DOI: 10.1148/ rg. 272055098.

32. Kim WY, Kim WS, Kim I, et al. Sonographic evaluation of neonates with early-stage necrotizing enterocolitis. Pediatr Radiol 2005;35(11): 1056-1061. DOI: 10.1007/s00247-005-1533-4.

33. Rath C, Suryawanshi P. Point of care neonatal ultrasound-head, lung, gut and line Localization. Indian Pediatr 2016;53(10):889-899. DOI: 10.1007/s13312-016-0954-5.

34. Leonidas JC, Krasna IH, Fox HA, et al. Peritoneal fluid in necrotizing enterocolitis: a radiologic sign of clinical deterioration. J Pediatr 1973;82(4):672-675. DOI: 10.1016/S0022-3476(73)80594-3.

35. Kim JH. Role of abdominal US in diagnosis of NEC. Clin Perinatol 2019;46(1):119-127. DOI: 10.1016/j.clp.2018.10.006.

36. Silva CT, Danemann A, Navarro OM, et al. Correlation of sonographic findings and outcome in necrotizing enterocolitis. Pediatr Radiol 2007;37(3):274-282. DOI: 10.1007/s00247-006-0393-x. 